\title{
Marcas de oralidade no texto escrito
}

\author{
Joyce Elaine de ALMEIDA BARONAS *
}

Resumo: O processo de escrita se dá muito depois do processo de oralidade, ou seja, geralmente, quando a criança começa a escrever, já desenvolveu todo o processo de fala; portanto, é natural que haja a transposição da oralidade quando a criança inicia a arte da escrita. Este artigo pretende estudar a influência da oralidade no texto escrito e apresentar um paralelo entre os desvios da norma mais comuns e as marcas do falar rural. Para tanto, num primeiro momento, serão expostos alguns pressupostos teóricos sobre os desvios da norma padrão e, posteriormente, serão analisados dois corpora constituídos de textos de alunos e de entrevistas com falantes rurais a fim de compará-los e identificar uma provável relação.

Palavras-chave: Oralidade; Escrita; Ensino de língua portuguesa.

Abstract: The process of writing takes place long after the process of speech, ie, usually when the child begins to write, has already developed the entire speech, so it is natural that there is the implementation of oral when the child begins the art of writing. This article aims to study the influence of orality in the written text and make a parallel between the standard deviations of the most common brands of rural talk. Thus, at first, some theoretical assumptions about deviations from the standard pattern will be exposed and then two corpora consist of texts of interviews with students and rural speakers will be analyzed to compare them and identify a likely identification.

Keywords: Orality; Writing; Teaching Portuguese Language.

* Doutorado em Linguística e Língua Portuguesa pela UNESP. Docente da Universidade Estadual de Londrina. Contato: joyal@uel.br. 


\section{Introdução}

A língua portuguesa no Brasil é bastante diversificada devido a determinados motivos, como a extensa faixa territorial do país, que reúne falantes de um português diversificado, além dos fatores socioculturais que dinamizam as variações na língua. Com isso, a escola brasileira enfrenta questões complicadas no que diz respeito ao ensino da língua, pois os estudantes, muitas vezes, apresentam uma fala muito distante da norma padrão e, por isso, têm muita dificuldade na absorção de tal norma. É sabido que a norma padrão é uma prescrição da modalidade escrita; a norma culta seria a mais próxima desta norma, por ser baseada na fala de pessoas com bastante familiaridade com a escrita. Entretanto, há uma grande camada da população brasileira que não tem acesso à norma culta. Tal faixa populacional é também marginalizada em situações demarcadas pela cultura escrita, pois não domina suas regras. $\mathrm{O}$ falar rural já não se restringe a falantes residentes em regiões rurais. Muitos moradores da zona urbana apresentam traços desse falar, composto de fenômenos linguísticos diferentes da norma culta e que, ao contrário do que é apregoado por milhares de leigos sobre questões de língua, não constitui um falar "errado", mas uma forma linguística diferenciada, que conserva traços do português antigo. O presente estudo pretende, pois, estudar os desvios da norma padrão presentes em textos escritos e compará-los com fenômenos comuns no falar rural a fim de melhor compreender esses desvios, podendo fornecer subsídios ao professor de língua portuguesa no tratamento de tais ocorrências linguísticas. Para isto, na parte teórica, serão apresentadas algumas questões relacionadas à variação linguística; posteriormente, serão apontados estudos sobre o falar rural e, em seguida, serão comentados estudos a respeito dos desvios da norma. Já na parte analítica, serão comparados textos de alunos de uma escola de Cambé-PR com dados do falar rural de Paiquerê-PR, a fim de identificar algumas semelhanças, buscando comprovar a influência da oralidade no texto escrito. 


\section{Pressupostos teóricos}

\subsection{Variação linguística}

A linguagem é, por natureza, um objeto sujeito a alterações, por ser uma parte constitutiva do ser humano. Ora, se o homem está sempre evoluindo, mudando sua aparência, suas idéias, seus valores, é perfeitamente normal haver variações e mudanças linguísticas. Segundo Labov (1962), a variação linguística é natural, é essencial à linguagem humana. Desta forma, o que exigiria explicação seria a ausência da variação na linguagem e não a sua presença.

Meillet já apontava, em 1906, o fato social como motivação fundamental para ocorrerem alterações linguísticas: "Por ser a língua um fato social resulta que a lingüística é uma ciência social, e o único elemento variável ao qual se pode recorrer para dar conta da variação lingüística é a mudança social" (MEILLET apud CALVET, 2002, p. 16).

$\mathrm{Na}$ mesma linha de pensamento, Coseriu (1980) afirma que a diversidade linguística pode ocorrer devido a diversos fatores e propõe uma classificação para as diferentes formas de variação: diacrônica, diatópica, diastrática e diafásica. Segundo o autor, quando há alterações linguísticas resultantes da passagem do tempo, elas se denominam diacrônicas. Como exemplo para este tipo de variação há o pronome você, enquanto resultado das mudanças na expressão Vossa Mercê.

As variações resultantes das características regionais, ou diatópicas, são representadas pelos distintos sotaques, evidenciados, por exemplo, pela diferente pronúncia do $\mathbf{r}$ em regiões paulistas e regiões nordestinas. Além dessas, as variações diatópicas também se evidenciam em outros níveis, como o lexical, por exemplo, com os variados nomes existentes para um mesmo objeto; ou o morfossintático, como a distribuição regional do emprego do pronome tu/você.

Há também as alterações na linguagem resultantes dos diferentes estratos socioculturais, denominadas diastráticas e que 
podem ser comprovadas com estudos comparativos entre falantes alfabetizados e analfabetos, por exemplo.

Finalmente, existem as variações diafásicas, que, segundo o estudioso, são as distinções entre os diversos tipos de modalidade expressiva. Para o autor, "as variedades lingüísticas que caracterizam - no mesmo estrato social - os grupos 'biológicos' (homens, mulheres, crianças, jovens) e os grupos profissionais podem ser consideradas como 'diafásicas'.” (COSERIU, 1980, p. 110-111).

Tais apontamentos são de relevância para o presente estudo porque se defende aqui a interferência da fala na escrita, e, como afirma Cagliari (1999, p. 124), "a variação lingüística, característica inerente a toda e qualquer língua do mundo, pode constituir um grande problema para quem está adquirindo o sistema da escrita." Isto porque $\mathrm{o}$ aluno pode transpor as variantes distantes da norma para o texto escrito. Em outro estudo, o autor ainda aponta que "o erro mais comum dos alunos é caracterizado por uma transcrição fonética da própria fala" (CAGLIARI, 1992, p. 138).

\subsection{Falar rural}

O falar rural constitui rica fonte de estudo por conservar traços do português antigo; trata-se de uma linguagem bastante conservadora pelo fato de concentrar-se em regiões distantes da urbanização onde impera a cultura escrita. Entre os trabalhos que abordam as variedades rurais, serão comentados os trabalhos de Amaral (1920), de Rodrigues (1974), de Veado (1982) e de Penha (1997).

Amaral (1920) enfoca o falar característico de moradores de zona rural paulista, nomeando-o dialeto caipira. Em seu estudo, o autor afirma que o dialeto caipira sofreu alterações em função do meio social, mas ainda existe em determinadas regiões:

Hoje, ele (o dialeto caipira) acha-se acantoado em pequenas localidades que não acompanharam de perto o movimento geral do progresso e subsiste, fora daí, na boca de pessoas idosas, indelevelmente influenciadas pela antiga educação. 
Entretanto, certos remanescentes do seu predomínio de outrora ainda flutuam na linguagem corrente de todo o Estado, em luta com outras tendências, criadas pelas novas condições. (AMARAL, 1920, p. 42) ${ }^{1}$

Para apresentar as distinções entre o dialeto caipira e o padrão, o pesquisador destaca, em seu estudo, questões relacionadas à fonética, à morfologia, à sintaxe e ao vocabulário.

Em relação à fonética, o autor afirma serem os fonemas do dialeto caipira em geral os mesmos do português, apesar de existirem algumas variantes fisiológicas características de cada povo. Segundo o autor, para essas variantes, "só a fonética experimental poderia dar uma noção precisa” (AMARAL, 1920, p. 47).

Sobre o aspecto lexicológico, o pesquisador aponta o caráter restrito do vocabulário do dialeto caipira, resultante da simplicidade de vida de seus falantes. Conforme Amaral (1920), o vocabulário desse dialeto é formado:

a) de elementos oriundos do português usado pelo primitivo colonizador, muitos dos quais se arcaizaram na língua culta; b) de termos provenientes das línguas indígenas;

c) de vocábulos importados de outras línguas, por via indireta;

d) de vocábulos formados no próprio seio do dialeto. (AMARAL, 1920, p. 55)

O vocabulário é apresentado pelo autor a partir de um glossário de brasileirismos correntes em São Paulo. Segundo o autor, tal glossário é composto "de vocábulos em uso entre os roceiros, ou caipiras, cuja linguagem, a vários respeitos, difere bastante da da gente das cidades, mesmo inculta" (AMARAL, 1920, p. 82).

\footnotetext{
${ }^{1}$ Ressalta-se que, atualmente, o falar rural, embora se encontre disperso, espalha-se pelas diversas regiões rurais do Brasil.
} 
Ao abordar as questões de ordem morfológica, o pesquisador enfatiza que o dialeto caipira foi bastante fértil, dada "a formação de numerosos substantivos e adjetivos, quer por composição, quer por derivação" (AMARAL, 1920, p. 68).

Para comentar a sintaxe, o estudioso ressalta que a complexidade dos fenômenos sintáticos dificulta uma sistematização e acrescenta que "só depois de acumulado muito material e depois de este bem verificado e bem apurado é que se poderão ir procurando as linhas gerais da evolução realizada, e tentando dividi-lo em classes" (AMARAL, 1920, p. 74).

Com esta abordagem, Amaral reúne um interessante material, compondo uma espécie de dicionário do léxico rural.

Rodrigues (1974) também aborda o falar rural. A autora aponta a existência do "dialeto caipira", em 1969, na região de Tietê e Porto Feliz:

Constatou-se, guardadas as devidas cautelas impostas pelos rápidos contatos e sem escolha rigorosa de locutores, que o chamado dialeto caipira, ao contrário do que previa Amadeu Amaral, poderia ainda existir com apreciável vitalidade. (RODRIGUES, 1974, p. 21)

A partir desta verificação, Rodrigues (1974) se ocupou da análise da fala de informantes da região de Piracicaba, por meio de critérios morfossintáticos, fonéticos e fonológicos. Como resultado de seu trabalho, conclui que seu objeto de estudo - a fala de moradores de Piracicaba - constitui-se num dialeto:

Pode-se, portanto, pensar em uma forma divergente da língua-padrão, num grupo específico, numa área geográfica restrita. Os resultados obtidos levam, assim, à conclusão de que se trata de um dialeto. No consenso dos moradores da área urbana, este dialeto é uma fala 'caipira' e os próprios informantes têm consciência disso quando, para fugir à conotação pejorativa que se atribui ao caipira, tentam 'melhorar' os seus recursos de expressão (RODRIGUES, 1974, p. 170). 
O falar rural é também estudado por Veado (1982), com base na descrição e análise da língua falada por informantes não escolarizados, residentes em zonas rurais da região Sanfranciscana Januária, Minas Gerais, a fim de fornecer dados para a elaboração de materiais didáticos de leitura e escrita adequados àquela clientela. Tal estudo tem o objetivo, também, de dar subsídios para trabalhos sobre diferenças linguísticas, contribuindo para baixar o alto índice de analfabetismo dos moradores da zona rural. Conforme aponta a pesquisadora, um dos grandes motivos do analfabetismo reside no desconhecimento da realidade linguística (e pragmática) da clientela a ser alfabetizada, por parte dos docentes e/ou por parte, principalmente, dos responsáveis pela elaboração do material de leitura e escrita destinado à alfabetização do adulto da zona rural (VEADO, 1982, p. 9).

Segundo a pesquisadora, o educador, diante da linguagem rural diferenciada, deve optar por formas mais simples, como por exemplo, o 'a gente' em vez do 'nós', nos casos de concordância verbal, e só posteriormente introduzir a concordância padrão.

Uma das conclusões da autora foi a verificação de que "as formas lingüísticas em uso efetivo no dialeto rural são também bastante usadas no português coloquial urbano" (VEADO, 1982, p. 97). Para Veado, algumas formas - tais como o 'se' indeterminado, o 'se' reflexivo, a passiva 'ser -do', o futuro do subjuntivo, o presente do subjuntivo e a relativização regida de preposição - estão se extinguindo da língua falada em geral, tanto rural como urbana, e estão se tornando cada vez mais exclusivas da língua escrita.

Outro pesquisador que toma o falar rural como objeto de estudo é Penha (1997), que trata da relação existente entre os textos regionalistas, a fala popular e os textos antigos. Segundo o autor, em seu trabalho

[...] está a prova de que os escritores regionalistas são em geral fiéis às formas da fala popular, e estas, por sua vez, repetem muitas que usaram os escritores antigos, especialmente os que escreveram no século XVI e XVII, fase de início e prosseguimento da colonização brasileira. (PENHA, 1997, p. 14) 
Para a elaboração de seu estudo, o pesquisador comparou estudos por ele realizados anteriormente: $A$ Arcaicidade da Lingua Popular Brasileira (1971), Aspectos da linguagem de São Domingos (1972), Vocabulário Rural-Mineiro (1976), A Linguagem de Mário de Andrade (1974), Os Lusíadas de Camões e o Português Popular do Brasil (1977) e a Variante Rural de Minas na Literatura Regional do Brasil (1981), além de uma vasta bibliografia literária, de textos arcaicos e de estudos dialetológicos.

A partir desse trabalho, o autor comprova a conservação do português antigo na linguagem popular.

Com base nesses dados, pode-se reafirmar o caráter conservador deste falar, forma linguística peculiar, que apresenta dados muito interessantes para a pesquisa sobre a língua. Deste modo, não se pode afirmar que tal dialeto seja destoante e sem razão de ser, pois traz, em suas formas diversas, traços da língua portuguesa em sua formação.

\subsection{Desvios da norma}

O texto escrito, como é sabido, exige a norma padrão. Entretanto, é comum a existência de dificuldades dos alunos na assimilação desta norma, gerando incorreções de ordem gramatical e ortográfica. Câmara Jr., em artigo publicado em 1957, já estudava os chamados "erros escolares". Em seu estudo, o autor analisou textos de alunos de escolas particulares do Rio de Janeiro, identificando desvios da norma padrão e apontando os fenômenos ocorridos. Os textos analisados eram resultantes de ditados e de algumas questões de ordem gramatical e o autor os analisou classificando-os em três aspectos: fonético, morfológico e sintático. Salienta-se que, entre os 20 itens apontados pelo autor, 13 são de ordem fonética, ou seja, dizem respeito à oralidade presente no texto escrito. Finalizando seu estudo, o autor reforça a idéia da influência da oralidade na escrita ao apontar que seu objetivo, ao efetuar tal estudo, era "documentar certas tendências coletivas da língua coloquial no Brasil, ou mais especialmente no Rio de Janeiro" (CÂMARA JR, 1957, p. 95). 
Miriam Lemle (1978) também aborda os desvios da norma em textos de alunos do MOBRAL-Rio. A autora efetuou seu estudo a partir da Sociolinguística Quantitativa, identificando regras variáveis que dependem de contextos linguísticos e sociais. Paiva (1984), sob orientação de Miriam Lemle, também analisou questões relativas à norma em sua dissertação de mestrado em que compara textos de alunos de uma escola municipal do norte do Rio de Janeiro com textos de alunos de uma escola particular da zona sul da cidade. A pesquisadora identificou "erros" resultantes da interferência da oralidade e "erros" ortográficos, concluindo que o dialeto dos alunos da escola municipal era o fator responsável pelo maior número de "erros" comparados com os de escola particular.

Outra pesquisa direcionada a tal fenômeno é a de BortoniRicardo (2005), na qual aplica a técnica de análise e diagnose de erros que, segundo a autora, "permite a identificação dos erros, bem como a elaboração de material didático destinado a atender às áreas cruciais de incidência" (2005, p.53).

A autora aponta quatro categorias de erros, que se seguem:

1) Erros decorrentes da própria natureza arbitrária do sistema de convenções da escrita;

2) Erros decorrentes da interferência de regras fonológicas categóricas no dialeto estudado;

3) Erros decorrentes da interferência de regras fonológicas variáveis graduais;

4) Erros decorrentes da interferência de regras fonológicas variáveis descontínuas. (BORTONI-RICARDO, 2005, p. 54)

Como se pode constatar, apenas a primeira categoria não tem relação com a oralidade, pois diz respeito à questão ortográfica. Um exemplo desta ocorrência seria a troca de letras com semelhança fonética, como em tassal taça. As outras três, como afirma a pesquisadora, são "decorrentes da transposição dos hábitos da fala para a escrita” (2005, p. 54) e se distiguem entre si. A segunda categoria se caracteriza pela interferência de regras fonológicas categóricas, ou seja, seriam fenômenos sempre presentes no dialeto 
em questão. Um exemplo dessa ocorrência seria a "neutralização das vogais anteriores /e/ e /i/ e das posteriores /o/ e /u/ em posição pós-tônica ou pretônica" (2005, p. 56), como em cantul canto. A terceira categoria se constitui da influência de regras fonológicas variáveis graduais, portanto diz respeito a ocorrências que dependem de determinados fatores, pelo fato de serem variáveis, e que não são estigmatizadas, pelo fato de serem graduais. Um exemplo deste fenômeno seria a monotongação de ditongos decrescentes, como em fera/feira. A última categoria se distingue da terceira por se tratar de fenômenos que diferenciam os falantes e os definem, estando "presentes no repertório verbal de alguns estratos e ausentes na linguagem dos demais" (2005, p. 56). Um exemplo desse fenômeno seria a ausência de concordância verbal, como, por exemplo, em nóis vai.

A autora utiliza o termo "erros" para os desvios da norma e, em estudo realizado em 2006, justifica a utilização de tal termo. Segundo Bortoni-Ricardo (2006), a fala prevê a variação, já a escrita não, ou seja, devem-se respeitar as variadas formas de expressão linguística na modalidade oral; entretanto, "na modalidade escrita, a variação não está prevista quando uma língua já venceu os estágios históricos da sua codificação. A uniformidade de que a ortografia se reveste garante sua funcionalidade" (2006, p. 273). BortoniRicardo ainda comenta o papel do professor na tarefa de corrigir os alunos na modalidade escrita e afirma:

Considerar uma transgressão à ortografia como um erro não significa considerá-la uma deficiência do aluno que dê ensejo a críticas ou a um tratamento que o deixe humilhado. O domínio da ortografia é lento e requer muito contato com a modalidade escrita da língua. Dominar bem as regras de ortografia é um trabalho para toda a trajetória escolar e, quem sabe, para toda a vida do indivíduo.

O presente estudo não utilizará o termo "erro", entretanto corrobora as idéias de Bortoni-Ricardo ao afirmar que a escrita não permite a variação linguística. 


\section{Análise dos dados}

Nesta parte, serão comparados (i) dados extraídos da monografia de Lini (2007), em que a estudiosa analisou textos de alunos da $4^{\mathrm{a}}$ série do ensino fundamental de uma escola pública de Cambé-PR buscando os desvios da norma e comparou-os com dados de manuscritos do século XVIII e (ii) dados extraídos da tese de Almeida Baronas (2005), em que a pesquisadora analisou a fala de informantes da zona rural buscando traços do falar rural. Tal comparação se dará com o objetivo de identificar uma possível relação entre as marcas do falar rural e os traços comuns aos desvios da norma, comprovando a provável interferência da fala na escrita. A composição dos corpora se justifica pela proximidade temporal e local: enquanto o estudo de Lini se deu em 2007, na cidade de Cambé-PR, muito próxima a Londrina-PR; o de Almeida Baronas, se deu em 2005, em Paiquerê, distrito da cidade de Londrina.

A seguir, serão apresentados os fenômenos ocorridos nos textos dos alunos da escola de ensino fundamental para posteriores comentários a partir dos casos presentes no falar rural. Ressalta-se que houve uma seleção dos dados, uma vez que se buscou identificar o que há em comum entre os dois corpora: ${ }^{2}$
a) neutralização das vogais e e $i$ (LINI, 2007, p. 39);
b) neutralização das vogais $o$ e $u$ (LINI, 2007, p. 39);
c) monotongação de ditongos decrescentes (LINI, 2007, p. 40);
d) queda do /r/ final nas formas verbais (LINI, 2007, p. 40);
e) ditongação (LINI, 2007, p. 41).
O item (a) é comprovado com a presença, no corpus, dos termos presenti, conviti, consigui, bronsiar/bronsiada e o item (b) com o termo engulia. Trata-se da interferência do fenômeno alçamento,

\footnotetext{
${ }^{2}$ Os casos que se restringem à questão ortográfica, por exemplo, por dizerem respeito às próprias convenções da escrita, não estão presentes, já que ocorrem apenas no texto escrito
} 
comum no falar rural. No estudo de Almeida Baronas ocorre tal fenômeno em diversos momentos de fala dos informantes, ocorridos nos seguintes termos: nutícia (AM), prifiru (AM), ligitimu $(\mathrm{AM})$, dipois $(\mathrm{CM})$, impididu $(\mathrm{CM})$, mintira $(\mathrm{CM})$, pricisa $(\mathrm{CM})$, iscutu (FF), subrinha (FF), siguinu (FF), sigui (FF), siguru (GM), istudu (HF) ${ }^{3}$ (ALMEIDA BARONAS, 2005, p. 102).

Nesses vocábulos, ocorre o fenômeno do alçamento, fato considerado natural no dialeto caipira por Amaral (1920, p. 49).

Castro (1995) estudou a harmonização vocálica - "elevação ou fechamento das pretônicas /e/ e /o/ e/i; o/u seguidas de uma tônica alta (/i/ ou /u/)" (CASTRO, 1995, p. 243) nos dados do Atlas Prévio dos Falares Baianos (APFB) e verificou que a tônica alta é um fator de desfavorecimento da abertura das pretônicas. A autora pesquisou a ocorrência de 29 vocábulos que considerou relevantes para tal estudo e constatou que "a elevação das pretônicas /e/ e /o/, quando seguidas de tônica alta, é uma tendência bastante notável na Bahia", reconhecendo o contexto tônica alta como desfavorecedor da abertura das pretônicas /e/ e /o/.

É interessante ressaltar que essa alteração ocorre em outras variedades do português brasileiro e do português europeu, independentemente de se tratar de variedade urbana ou rural.

O item (c) ocorre nos termos hove, janero, mangedora, pexaria, quemadinho, presentes no corpus de Lini (2007, p. 40). Este fenômeno também se faz presente no corpus de Almeida Baronas (2005, p. 140-142) nos seguintes casos:

1) monotongação de ei para e: di primeru $(\mathrm{BF})$, primera $(\mathrm{BF})$, bera $(\mathrm{CM})$, cumpanheru $(\mathrm{CM})$, primeru $(\mathrm{CM}, \mathrm{HF}, \mathrm{DF})$, dinheru $(\mathrm{DF})$, infermera $(\mathrm{DF})$, dexava $(\mathrm{HF})$, dexô $(\mathrm{HF})$, tercera $(\mathrm{FF})$;

2) monotongação de ou para o: otru (AM, BF, GM, HF), ota (BF), istragô (CM), pocu (CM), $\hat{o}(\mathrm{DF} . \mathrm{EM})$, otu (DF), otus (DF), ropa (DF, HF), sô (DF, HF), vô (DF, EM), otra (GM, HF), tocô (HF), vortô (HF);

\footnotetext{
${ }^{3}$ As letras correspondem à ordem dos informantes (A/B/C/D...) e ao sexo (M e F).
} 
3) monotongação de ai para $a$ : baxu (GM).

Segundo Amaral, a redução de ei para $e$ se dá pelo contato com a consoante seguinte ao ditongo. Conforme aponta o autor, o ditongo $e i$ "reduz-se a ê quando seguido de r, x ou j" (AMARAL, 1920 , p. 50). Já em relação ao segundo caso de ditongos, o autor afirma que o ditongo ou, acentuado ou não, no dialeto caipira, contrai-se em $o$.

Embora Amaral descreva esse processo como próprio do dialeto caipira, pode-se afirmar que o fenômeno da monotongação se constitui num traço muito comum na língua falada em geral. Paiva (1998a) aborda tal tendência a partir da análise da redução de ditongos ocorrida em 44 entrevistas do Projeto Censo de Variação Lingüistica no Município do Rio de Janeiro. Para a autora, "a redução dos ditongos decrescentes (ew) e (ow) a vogais simples é mais um entre os diferentes processos de que a língua se utiliza para evitar cadeias sintáticas complexas" (PAIVA, 1998a, p. 234), não constituindo, pois, índice de variação diastrática, mas resultando de fatores estruturais. Em outro estudo, Paiva (1998b) procura analisar a relação entre a tendência de reduzir os ditongos e os fatores socioculturais. Para isto, verifica se variáveis estratificadas (escolarização, sexo, idade) e variáveis não estratificadas (mercado ocupacional, sensibilidade linguística, mídia e renda) influenciam a supressão da semivogal dos ditongos e conclui haver apenas uma leve e parcial influência das variáveis estratificadas escolarização e idade nos falantes adultos.

Portanto, pode-se afirmar que a redução dos ditongos já constitui um fenômeno natural na fala coloquial, não sendo uma característica estritamente relacionada ao falar rural nos dias atuais.

Melo (1981, p. 79), ao abordar tal processo, recusa a possibilidade de ele se dar por influência africana, conforme aponta Mendonça (1935, p. 118). Para Melo, tal fato resulta de influência latina. Paiva (1998a) segue a mesma idéia de Melo, afirmando que a tendência de evitar os ditongos é "atestada no português ao longo de toda a sua história” (1998a, p. 219), pois, no latim vulgar, já se evidenciava tal tendência.

Antes desses autores, Boléo (1943, p. 24) já afirmava: 
A redução dos ditongos ei a ê e ou a ô- bêjo, pêxe, ôro, 'dêxa de brincadêra'- não é facto lingüístico próprio do Brasil: encontra-se em várias regiões de Portugal, e com bastante freqüência. Na Beira Baixa, província que conheço melhor, é êle correntíssimo.

Reforçando as idéias citadas, Delgado (1951) apresenta em seu estudo casos de monotongação ocorridos em Portugal como, por exemplo, "otro" e "roxinol".

Também Cintra (1970) aponta a possibilidade da origem européia para tal fenômeno. O autor verificou a distribuição dos ditongos $o i$ e $e i$ e suas variantes em Portugal e constatou que, em determinadas regiões, se conservam os ditongos em sua forma original, noutras regiões os ditongos se alteram e há, também, a ocorrência da monotongação em algumas localidades.

O item (d) se apresenta no seguinte termo do corpus de Lini (2007, p. 40): viajá. Trata-se do fenômeno fonético classificado como apócope, também presente na tese de Almeida Baronas (2005, p. 154) nos termos: muié (AM: 6, 7), qualqué (BF:), quisé (BF), pai (CM), $i(\mathrm{DF})$

Segundo Amaral (1920), no dialeto caipira tal ocorrência é comum. Melo (1981, p. 81) entende que tal ensurdecimento seja uma influência latina, recusando a tese de Mendonça (1935, p. 115) de que haja aí uma influência africana. A supressão de segmentos em fim de palavra é um processo que caracteriza o latim vulgar e que se manteve presente e atuante na história das línguas latinas.

Boléo (1943) afirma que, em Portugal, "a supressão do r em frases é ainda mais freqüente nos falares populares." Com isso, a origem européia é a mais provável.

O item (e) ocorre nos seguintes termos da monografia de Lini (2007, p. 41): pessouas, voceis, voua. Tal processo se identifica nas seguintes expressões do corpus de Almeida Baronas (2005, p. 142-143): às vei ( $\mathrm{AM}$ ), faiz ( $\mathrm{AM}, \mathrm{BF}, \mathrm{CM}, \mathrm{DF})$, gáis (AM), mêis (AM, CM, EM, GM), luiz (CM, FF), nóis (CM, DF), trêis (GM, $\mathrm{HF}), \operatorname{veiz}(\mathrm{GM}, \mathrm{HF})$. 
Identifica-se, nesses vocábulos, o processo de ditongação das vogais seguidas de fricativas, fenômeno apontado por Amaral (1920, p. 48), ao abordar as vogais do dialeto caipira: "As tônicas, em regra geral, não sofrem alteração. $\mathrm{O}$ único fato a assinalar com relação a estas é que, quando seguidas de ciciantes (s ou z), no final dos vocábulos, se ditongam pela geração de um i: rapaiz, mêis, péis, nóis, lúiz."

Apesar de Amaral considerar o processo de ditongação como marca do falar rural, tal traço é muito comum na fala de muitas localidades, como no Rio de Janeiro, por exemplo.

Pode-se perceber, pela análise dos dados, que há uma semelhança entre os dados selecionados do corpus do trabalho de Lini (2007) e os dados de Almeida Baronas (2005). A neutralização das vogais, a monotongação, a apócope e a ditongação, que são fenômenos comuns no falar rural estudado por Almeida Baronas (2005), estão presentes nos textos de alunos de escola municipal, analisados por Lini (2007), o que pode indicar uma provável relação entre os dois corpora, ou seja, traços do falar rural já não se reduzem a este falar, estando também presentes no texto escrito.

\section{Considerações finais}

A modalidade escrita se diferencia da modalidade oral por diversos fatores, pode-se até afirmar que são línguas distintas, pois não é possível transpor as normas da fala para escrita nem as da escrita para as da fala. Apesar disso, é comum que haja tal transposição da oralidade no processo da escrita, principalmente quando o aluno não tem familiaridade com esta modalidade, ocorrendo incorreções de várias ordens. O presente estudo pretendeu constatar tais afirmações, procurando observar características do texto oral no escrito, mais especificamente do falar rural no texto de alunos de escola pública. A partir da análise dos dados, contatou-se a relação entre os corpora em estudo, pois verificou-se que muitas características do falar rural já são presentes na fala coloquial de uma grande parcela da população e não são, necessariamente, restritas a falantes da zona rural. Além disso, 
constatou-se que tais traços se estendem à modalidade escrita, comprovando a influência da oralidade na escrita. Com isto, esperase contribuir com o ensino de Língua Portuguesa, levando o professor a repensar sua prática de correção de textos, considerando os aspectos aqui levantados a fim de que possa agir com maior segurança e eficiência na sala de aula, pois, a partir do momento em que ele souber o motivo pelo qual os alunos apresentam dificuldades na escrita, saberá como lidar com elas.

\section{Referências}

ALMEIDA BARONAS, Joyce Elaine de. www.fogãoalenha.com.br: a influência da urbanização na fala de informantes rurais. 2005. 272p. Tese (Doutorado em Linguística e Língua Portuguesa) - Universidade Estadual Paulista Júlio de Mesquita Filho, Araraquara.

AMARAL, Amadeu. O dialeto caipira. São Paulo: Anhembi, 1920.

BOLÉO, Manuel de Paiva. Brasileirismos: problemas de método. Coimbra: Coimbra, 1943.

BORTONI-RICARDO, Stella Maris. O estatuto do erro na língua oral e escrita. In: GORSKI, Edair Maria; COELHO, Izete Lehmkuhl (Orgs.) Sociolingüística e ensino: contribuições para a formação do professor de língua. Florianópolis: EdUFSC, 2006.

Nós cheguemu na escola e agora?: sociolingǘstica e educação. São Paulo: Parábola, 2005.

CALVET, Louis-Jean. Sociolingüística: uma introdução crítica. São Paulo: Parábola, 2002.

CAGLIARI, Luiz Carlos. Diante das Letras: a escrita na alfabetização. São Paulo: Fapesp, 1999.

1992.

Alfabetização e lingüística. 5. ed. São Paulo: Scipione, 
CÂMARA JR, Joaquim Mattoso. Erros escolares como sintomas de tendências lingüísticas no português do Rio de Janeiro. In: Dispersos. Rio de Janeiro: Fundação Getúlio Vargas, 1972.

CASTRO, Vandersí Sant'Anna. A harmonização vocálica na Bahia (dados do APFB). ALFA, São Paulo, v. 39, p. 243-250, 1995.

CINTRA, Luís Filipe Lindley. Os ditongos decrescentes ou e ei: um esquema de um estudo sincrônico e diacrônico. In: SIMPÓSIO DE FILOLOGIA ROMÂNICA, 1., Rio de Janeiro, 1958. Anais... Rio de Janeiro: MEC, 1970. p. 115-134.

COSERIU, Eugenio. Lições de lingüística geral. Rio de Janeiro: Ao Livro Técnico, 1980.

DELGADO, Manuel Joaquim. A linguagem popular do Baixo Alentejo. [S. 1: s. n.], 1951.

LABOV, William. The social history of sound change on the island of Martha's Vineyard, Massachusetts. Master's essay. Columbia University, 1962.

LEMLE, Miriam. Heterogeneidade dialetal: um apelo à pesquisa. Tempo Brasileiro, n. 53/54 (Lingüística e Ensino do Vernáculo), p. 60-94, 1978.

LINI, Vanessa. A escrita de alunos do ensino fundamental: uma visão diacrônica. 2007. 57 p. Monografia (Especialização em Língua Portuguesa) - Universidade Estadual de Londrina, Londrina.

MELO, Gladstone Chaves de. A língua do Brasil. 4. ed. Rio de Janeiro: Padrão, 1981.

MENDONÇA, Renato. A origem africana no português do Brasil. 2. ed. São Paulo: Companhia Editorial Nacional, 1935.

PAIVA, Maria da Conceição Auxiliadora. Supressão das semivogais nos ditongos decrescentes. In: SILVA, Giselle Machline de Oliveira; 
SCHERRE, Maria Marta Pereira. Padrões sociolingüísticos: análise de fenômenos variáveis do português falado na cidade do Rio de Janeiro. 2. ed. Rio de Janeiro: Tempo Brasileiro, 1998a. p. 217-236.

Atuação das variáveis sociais na supressão das semivogais anteriores nos ditongos decrescentes. In: SILVA, Giselle Machline de Oliveira; SCHERRE, Maria Marta Pereira. Padrões sociolingüísticos: análise de fenômenos variáveis do português falado na cidade do Rio de Janeiro. 2. ed. Rio de Janeiro: Tempo Brasileiro, 1998b. p. 325-333.

Variação dialetal e aprendizagem de ortografia. In: ENCONTRO NACIONAL DE LINGÜÍSTICA, 8., Rio de Janeiro, 1984. Anais... Rio de Janeiro: PUC, 1984. p. 123-129.

PENHA, João Alves Pereira. Português rural de Minas numa visão tridimensional. Franca: UNESP, 1997.

RODRIGUES, Ada Natal. O dialeto caipira na região de Piracicaba. São Paulo: Ática, 1974.

VEADO, Rosa Maria Assis. Comportamento lingüístico do dialeto rural - MG. Belo Horizonte: UFMG/PROED, 1982. 